\title{
Immediate Postpartum Haemorrhage at the Libreville University Hospital Centre: Epidemiological Profile of Women
}

\section{SYLVAIN HONORE WOROMOGO ( $\square$ woromogos@gmail.com )}

Centre Inter Etats d'Enseignement Supérieur en Santé Publique d'Afrique Centrale (CIESPAC) https://orcid.org/0000-0002-4459-0597

\section{Nathalie Ambouda Ledaga}

University Hospital Centre of Libreville

\section{Felicite-Emma Yagata-Moussa}

Faculty of Health Sciences, University of Bangui

\section{Liela Agnes Okoyi Ossouka}

Army Training Hospital Omar Bongo Ondimba, Libreville, Gabon

\section{Vicky Noel Simo Tekem}

National cancer Prevention and Control Programme, Ministry of Public Health, Gabon

\section{Eliane Okira Ango}

Health Centre Nzeng Ayong, Libreville, Gabon

\section{Alain Jepang Kouanang}

University Hospital Centre of Libreville, Gabon

\section{Research}

Keywords: Epidemiological profile, Immediate postpartum haemorrhage, Libreville

Posted Date: May 20th, 2020

DOI: https://doi.org/10.21203/rs.3.rs-27437/v1

License: (c) (1) This work is licensed under a Creative Commons Attribution 4.0 International License. Read Full License 


\section{Abstract}

\section{Introduction}

In Gabon, the frequency of maternal deaths directly related to Immediate PostPartum Haemorrhage (IPPH) is 15 to $25 \%$, despite the different means that World Health Organization (WHO) has made available to the providers of the Emergency Obstetrical and Neonatal Care (EmONC). The objective of this study was to determine the prevalence and epidemiological characteristics of IPPH in order to improve its management and reduce the rate of maternal deaths.

\section{Methods}

An analytical retrospective study involved 42,728 records, whose data were collected using a chart collection form on the basis of information contained in partograms and other patient records. The description of the sample is made using numbers and proportions. The relationship between the etiologies of IPPH and certain characteristics of the women was established using the ORs with their $95 \%$ confidence interval. The difference was significant if $p<0.05$.

\section{Results}

The prevalence of IPPH was 1.6\%. The 20-39 age group was the most represented. Multiparous women accounted for $67.2 \%$. Delivery hemorrhages accounted for $65.5 \%$ of IPPH. The main factors associated with delivery hemorrhages were multiparity $(p<0.001)$, preterm and postterm $(p<0.001)$, and child weight $>4,000 \mathrm{~g}(\mathrm{p}<0.001)$. Those associated with genital track injuries were young maternal age, multiparity $(p<0.001)$.

\section{Conclusions}

The prevalence of IPPH was $1.6 \%$. The most common etiology was hemorrhage from delivery. Multiparity remains the most common risk factor and the young age of the patients. It is important to improve management through better assessment of blood loss in the immediate postpartum as well as capacity building of health providers on EmONC.

\section{Plain English Summary}

Postpartum haemorrhage remains the main cause of maternal death throughout the word particularly in devloping countries. The majority of these deaths are preventable when there is adequate management of IPPH. This study, which took place at the level of a reference hospital, allowed us to characterize IPPH with its causes and risk factors.

Over a period of time, we have identified 42728 childbirth cases, among which there are 671 cases of IPPH. The majority of parturients $(n=584 / 671)$ had arrived at the University Hospital Centre on their own and by their own efforts, $87 \%$. There are two main categories of causes of IPPH, including delivery 
haemorrhages dominated by retroplacental haematoma and placenta previa, and trauma to the genital tract.

We observed that primigravidae such as primiparous $(p<0.001)$, multigravidae $(p<0.001)$ as well as multiparous ( $p=0.047)$ women had a lower risk of IPPH compared to women with $2-3$ pregnancies or 23 children. Women with preterm $(p=0.005)$ and postterm $(p<0.001)$ births were more likely to have IPPH than women with full-term births. In contrast, women with duration of labour more than 12 hours had significantly more IPPH than women with less than 12 hours

Factors associated with genital tract trauma were being $14-19$ years of age $(p<0.001)$, pauciparum ( $p<$ $0.001)$, full-term delivery $(p<0.001)$ and having a child weighing between $2500-4000 \mathrm{~g}(p<0.001$

\section{Introduction}

Immediate postpartum hemorrhage (IPPH) is defined as the loss of $500 \mathrm{~mL}$ or more of blood within 24 hours of delivery (1-3). In developing countries and sub-Saharan Africa, it is the leading direct cause of maternal death $(2,4,5,6,7)$. In Gabon, the frequency of maternal deaths directly related to IPPH is clearly increasing at the Libreville University Hospital Centre. It increased from 15-25\% between 2013 and 2015 (8), despite the various means that WHO has made available to EmONC providers such as the implementation of recommended protocols on the management of postpartum haemorrhage. Some of these deaths were preventable $(9-11)$. The objective of this study was to determine the prevalence and epidemiological characteristics of IPPH at Libreville University Hospital Centre with the aim of improving its management and reducing the rate of maternal deaths.

\section{Methods}

\section{Purpose and type of study}

This was an analytical retrospective study over a 5-year period from January 1, 2010 to December 31, 2014 , based on the systematic collection of immediate postpartum hemorrhage case files that occurred during this period. The study took place in the Department of Gynecology and Obstetrics of the University Hospital Centre of Libreville.

\section{Study Population And Sampling}

The study population is represented by all parturients admitted to the Department of Gynaecology and Obstetrics during the study period, $n=42728$. Included were all vaginal deliveries and cesarean deliveries with immediate postpartum hemorrhage. Not included were deliveries with late postpartum hemorrhage, postabortion hemorrhage, and rectorrhage or hematuria. All the records of parturients admitted to the Gynaecology and Obstetrics Department of the University Hospital Centre of Libreville who had presented an immediate postpartum haemorrhage and who were registered were collected. The data were collected 
using a collection form. The form was filled in on the basis of information contained in partogrammes, birth registers, operative report registers, anaesthesia and reanimation registers and hospitalization registers.

\section{The Variables}

The variables studied were sociodemographic characteristics, obstetric and gynecological history of the woman, characteristics of the pregnancy, the conduct of delivery, and the etiologies of hemorrhage.

\section{Data Analysis}

The data was entered into an Excel database and analyzed using SPSS version 22. The sample is described using numbers and proportions. The relationship between the etiologies of IPPH and certain characteristics of the women was established using the ORs with their $95 \%$ confidence intervals. The difference was significant if $p<0.05$.

\section{Ethical Considerations}

The study has received the approval of the ethics committee and an authorization from the Direction of the University Hospital of Libreville.

\section{Results}

During the study period, 42,728 birth records were collected, with a prevalence of immediate postpartum hemorrhage of $1.6 \%(n=671)$.

\section{Socio-demographic Characteristics Of Women}

The age of parturients ranged from 14 to 46 years with a mean age of $26.9 \pm 6.6$ years. The $20-39$ age group was the most represented with just over half of the parturients $(n=337)$. The majority of patients were housewives or women without paid employment $(n=293)$ and students $(n=156 / 202)$. Other characteristics of the women are presented in Table 1. 
Table 1

Socio-demographic characteristics of women

\begin{tabular}{|lll|}
\hline Variables & Numbers & Percentage (\%) \\
\hline Age (years) & & \\
\hline $14-19$ & 100 & 14.9 \\
\hline $20-39$ & 542 & 80.8 \\
\hline Q 40 & 29 & 4.3 \\
\hline Profession & & \\
\hline Household & 302 & 45.0 \\
\hline Student & 202 & 30.1 \\
\hline Public servant & 167 & 24.9 \\
\hline Marital status & & \\
\hline Single & 622 & 92.7 \\
\hline Married & 49 & 7.3 \\
\hline Educational level & & \\
\hline Without education & 01 & 0.1 \\
\hline Primary / secondary & 567 & 84.5 \\
\hline Superior & 103 & 15.4 \\
\hline
\end{tabular}

\section{Women's Gynecological-obstetric History}

Table 2 presents the participants' gynecological and obstetrical history. Slightly more than half $(\mathrm{n}=$ $341 / 671)$ of the parturients $(50.8 \%)$ had no gynecological history at all. In the other half, abortion ( $n=$ $301 / 330$ ) was found in the majority, followed by extrauterine pregnancy and in utero fetal death. 
Table 2

Pregnancy and childbirth characteristics of women at Libreville University Hospital

\begin{tabular}{|c|c|c|}
\hline Variables & Numbers & Percentage (\%) \\
\hline Surgical history & 671 & \\
\hline Cesarean section & 07 & 1.1 \\
\hline Salpingectomy & 05 & 0.7 \\
\hline None & 659 & 98.2 \\
\hline Gynecological history & 671 & \\
\hline Abortion & 301 & 44.9 \\
\hline Extra uterine pregnancy and other antecedents & 13 & 1.9 \\
\hline No history & 357 & 53.2 \\
\hline Gesture & 671 & \\
\hline 1 & 167 & 24.9 \\
\hline $2-3$ & 216 & 32.2 \\
\hline$\nabla 3$ & 288 & 42.9 \\
\hline Parity & 671 & \\
\hline 1 & 220 & 32.8 \\
\hline $2-3$ & 279 & 41.6 \\
\hline$\otimes 3$ & 172 & 25.6 \\
\hline Gestational age at delivery & 671 & \\
\hline Term & 393 & 58.6 \\
\hline Pre-term & 224 & 33.4 \\
\hline Post term & 54 & 8.0 \\
\hline Types of pregnancy & 671 & \\
\hline Mono fetal & 654 & 97.5 \\
\hline Twin & 17 & 2.5 \\
\hline Starting labour upon arrival & 671 & \\
\hline Immediate & 345 & 51.4 \\
\hline
\end{tabular}




\begin{tabular}{|lll|}
\hline Variables & Numbers & Percentage (\%) \\
\hline After 3 hours & 326 & 48.6 \\
\hline Duration of labour & 671 & \\
\hline 12 hours & 636 & 94.8 \\
\hline 12 hours & 35 & 5.2 \\
\hline Method of delivery & 671 & \\
\hline Caesarean section & 346 & 51.6 \\
\hline Vaginal delivery & 325 & 48.4 \\
\hline Extraction mode & 671 & \\
\hline Without instrument & 664 & 97.8 \\
\hline Forceps & 07 & 2.2 \\
\hline Mode of delivery & 671 & \\
\hline Artificial & 386 & 57.5 \\
\hline Directed & 276 & 41.2 \\
\hline Spontaneous & 9 & 1.3 \\
\hline Birth weight (g)* & 688 & \\
\hline 叉2500 & 193 & 28.1 \\
\hline $2500-4000$ & 479 & 69.6 \\
\hline \& 4000 & 16 & 2.3 \\
\hline * 17 twin pregnancies & & \\
\hline
\end{tabular}

\section{Characteristics Of Pregnancy And Childbirth}

Prenatal follow-up was carried out by 647 parturients, or $96.4 \%$. Among those who had performed prenatal follow-up and whose records mentioned it, near $3 / 4(n=478 / 647)$ had performed at least 4 prenatal visits, or $73.9 \%$. The remaining quarter ( $n=169$ or $26.1 \%$ ) had made between 1 and 3 prenatal visits.

Of those who had completed prenatal follow-up, more than three-quarters $(n=498 / 647)$ had been followed by a midwife for prenatal visits, or $77 \%$. Of the remainder, some $(n=139$ or $21.5 \%)$ had been followed by a gynecologist, while the records of the others did not specify the provider of the antenatal 
visits. Among the records studied, twin pregnancies $(n=17)$ concerned $2.5 \%$ of parturients, while monofetal pregnancies $(n=654)$ concerned $97.5 \%$ (Table 2$)$.

The majority of parturients $(n=584 / 671)$ had arrived at the University Hospital Centre on their own and by their own efforts, $87 \%$. The remaining patients $(n=8)$ or $13 \%$ had been referred from other facilities. More than half of the parturients $(n=345)$ were not in labour when they were admitted, $51.4 \%$. The other half $(n=326)$ had been in labour for an average of three hours. Extended work of at least 13 hours was found in $5.2 \%$ of parturients $(n=17)$.

\section{Etiologies Of Immediate Postpartum Hemorrhage}

The main etiology of this study was hemorrhage of delivery in $65.5 \%$ of parturients, the majority of whom had a placental insertion defect $(n=311 / 439)$. Genital tract trauma was found as a second etiology $(n=$ 402), with cervical lacerations $(n=176 / 402)$ being the main cause. No pathology of haemostasis had been identified (Table 3).

Table 3

Distribution of parturients by causes of immediate postpartum hemorrhage

\begin{tabular}{|llll|}
\hline Etiologies & & Number & Percentage (\%) \\
\hline Hemorrhages of deliverance & Placental abruption & 24 & 3.6 \\
\cline { 2 - 4 } & Placenta prævia & $113^{*}$ & 16.8 \\
\cline { 2 - 4 } & Retroplacental hematoma & $199 *$ & 29.7 \\
\cline { 2 - 4 } & Uterine atony & 103 & 15.4 \\
\hline Trauma of the genital tract & Cervical laceration & 176 & 26.2 \\
\cline { 2 - 4 } & Vaginal laceration & 96 & 14.3 \\
\cline { 2 - 4 } & Perineal laceration & 44 & 6.6 \\
\cline { 2 - 4 } & Vulvar laceration & 4 & 0.6 \\
\cline { 2 - 4 } & Uterine rupture & 28 & 4.2 \\
\cline { 2 - 4 } & Episiotomy & 54 & 8.0 \\
\hline Coagulation disorder & & 0 & 0 \\
\hline Total & & 671 & 100.0 \\
\hline *: One parturient presented with both retroplacental hematoma and placenta previa. & & & \\
\hline
\end{tabular}

\section{Risk Factors For Immediate Postpartum Hemorrhage}


The etiologies of immediate postpartum hemorrhages were delivery hemorrhages and genital tract trauma.

We observed that primigravidae such as primiparous $(p<0.001)$, multigravidae $(p<0.001)$ as well as multiparous $(p=0.047)$ women had a lower risk of IPPH compared to women with 2-3 pregnancies or 23 children. Women with preterm $(p=0.005)$ and postterm $(p<0.001)$ births were more likely to have IPPH than women with full-term births. This was similarly the case for women with children weighing $<2500 \mathrm{~g}$

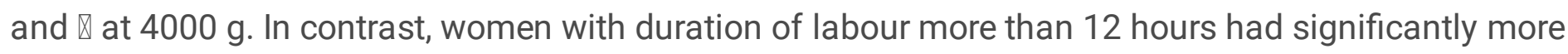
IPPH than women with less than 12 hours (Table 4). 
Table 4

Risk factors for IPPH in parturients

\section{Variables}

Maternal age

$\begin{array}{lllllllll}14-19 & 78 & 22 & \begin{array}{l}0.83(0.49- \\ 1.40)\end{array} & 0.49 & 97 & 3 & \begin{array}{l}11.26(3.51- \\ 36.09)\end{array} & 0.001 \\ 20-39 & 439 & 103 & 1.00 & - & 402 & 140 & 1.00 & - \\ 40+ & 21 & 8 & \begin{array}{l}0.61(0.26- \\ 1.43)\end{array} & 0.255 & 25 & 4 & \begin{array}{l}2.18(0.74- \\ 6.36)\end{array} & 0.145 \\ & & & & & & & \end{array}$

Gesture

\begin{tabular}{|c|c|c|c|c|c|c|c|c|}
\hline 1 & 40 & 127 & $\begin{array}{l}0.20(0.13- \\
0.32)\end{array}$ & $<.001$ & 70 & 97 & 1.00 & - \\
\hline $2-3$ & 131 & 85 & 1.00 & - & 79 & 137 & $\begin{array}{l}0.80(0.53- \\
1.21)\end{array}$ & 0.287 \\
\hline $4+$ & 96 & 192 & $\begin{array}{l}0.32(0.22- \\
0.47)\end{array}$ & $<.001$ & 92 & 196 & $\begin{array}{l}0.65(0.44- \\
0.96)\end{array}$ & 0.032 \\
\hline
\end{tabular}

Parity

\begin{tabular}{|c|c|c|c|c|c|c|c|c|}
\hline 1 & 39 & 181 & $\begin{array}{l}0.01(0.00- \\
0.02)\end{array}$ & $\begin{array}{l}< \\
0.001\end{array}$ & 120 & 100 & 1.00 & - \\
\hline $2-3$ & 265 & 14 & 1.00 & - & 196 & 83 & $\begin{array}{l}1.97(1.36- \\
2.85)\end{array}$ & $\begin{array}{l}< \\
0.001\end{array}$ \\
\hline $4+$ & 155 & 17 & $\begin{array}{l}0.48(0.23- \\
1.00)\end{array}$ & 0.047 & 20 & 133 & $\begin{array}{l}0.13(0.07- \\
0.22)\end{array}$ & $\begin{array}{l}<.001 \\
0.001\end{array}$ \\
\hline
\end{tabular}

Gestationnel age

\begin{tabular}{|c|c|c|c|c|c|c|c|c|}
\hline $\begin{array}{l}\text { Before } \\
\text { term }\end{array}$ & 116 & 108 & $\begin{array}{l}1.60(1.15- \\
2.22)\end{array}$ & 0.005 & 99 & 125 & 1.00 & - \\
\hline Term & 158 & 235 & 1.00 & - & 248 & 145 & $\begin{array}{l}2.16(1.55- \\
3.02)\end{array}$ & $\begin{array}{l}< \\
0.001\end{array}$ \\
\hline $\begin{array}{l}\text { Post } \\
\text { term }\end{array}$ & 74 & 17 & $\begin{array}{l}6.47(3.68- \\
11.38)\end{array}$ & $<.001$ & 35 & 56 & $\begin{array}{l}0.79(0.48- \\
1.29)\end{array}$ & 0.350 \\
\hline \multicolumn{9}{|l|}{ Duration of labour } \\
\hline$\leq 12 \mathrm{~h}$ & 377 & 259 & 1.00 & - & 469 & 167 & $\begin{array}{l}1.28(0.62- \\
2.68)\end{array}$ & 0.555 \\
\hline $12 \mathrm{~h}+$ & 31 & 4 & $\begin{array}{l}5.32(1.86- \\
15.26)\end{array}$ & $<.001$ & 24 & 11 & 1.00 & - \\
\hline
\end{tabular}

Duration of labour

\begin{tabular}{|c|c|c|c|c|c|c|c|c|}
\hline $\begin{array}{l}\text { Before } \\
\text { term }\end{array}$ & 116 & 108 & $\begin{array}{l}1.60(1.15- \\
2.22)\end{array}$ & 0.005 & 99 & 125 & 1.00 & - \\
\hline Term & 158 & 235 & 1.00 & - & 248 & 145 & $\begin{array}{l}2.16(1.55- \\
3.02)\end{array}$ & $\begin{array}{l}< \\
0.001\end{array}$ \\
\hline $\begin{array}{l}\text { Post } \\
\text { term }\end{array}$ & 74 & 17 & $\begin{array}{l}6.47(3.68- \\
11.38)\end{array}$ & $<.001$ & 35 & 56 & $\begin{array}{l}0.79(0.48- \\
1.29)\end{array}$ & 0.350 \\
\hline \multicolumn{9}{|l|}{ Duration of labour } \\
\hline$\leq 12 \mathrm{~h}$ & 377 & 259 & 1.00 & - & 469 & 167 & $\begin{array}{l}1.28(0.62- \\
2.68)\end{array}$ & 0.555 \\
\hline $12 \mathrm{~h}+$ & 31 & 4 & $\begin{array}{l}5.32(1.86- \\
15.26)\end{array}$ & $<.001$ & 24 & 11 & 1.00 & - \\
\hline
\end{tabular}

Genital tract trauma Yes No OR $(\mathrm{Cl} 95 \%) \quad p \quad$ Yes No OR (Cl 95\%) $\quad p$ Deliverance hemorrhage

Gesture 


\begin{tabular}{|c|c|c|c|c|c|c|c|c|}
\hline \multirow{2}{*}{$\begin{array}{l}\text { Variables } \\
\text { Birth weight }\end{array}$} & \multicolumn{4}{|c|}{ Deliverance hemorrhage } & \multicolumn{4}{|c|}{ Genital tract trauma } \\
\hline & & & & & & & & \\
\hline$<2500 \mathrm{~g}$ & 100 & 93 & $\begin{array}{l}2.72(1.92- \\
3.86)\end{array}$ & $<0.001$ & 96 & 97 & 1.00 & - \\
\hline $\begin{array}{l}2500- \\
4000\end{array}$ & 357 & 122 & 1.00 & - & 389 & 90 & $\begin{array}{l}4.37(3.04- \\
6.28)\end{array}$ & $\begin{array}{l}<.001 \\
0.0\end{array}$ \\
\hline$>4000$ & 4 & 12 & $\begin{array}{l}8.78(2.78- \\
27.73)\end{array}$ & $<.001$ & 11 & 5 & $\begin{array}{l}2.22(0.74- \\
6.64)\end{array}$ & 0.143 \\
\hline
\end{tabular}

Factors associated with genital tract trauma were being $14-19$ years of age $(p<0.001)$, pauciparum $(p<$ $0.001)$, full-term delivery $(p<0.001)$ and having a child weighing between $2500-4000 \mathrm{~g}(p<0.001)$. On the contrary, multiparous women were less likely $(p<0.001)$ to have a genital tract trauma (Table 4$)$.

\section{Discussion}

During data collection, we were confronted with the inherent limitations of any retrospective study: incomplete anamnestic information; non-exhaustive paraclinical explorations; missing medical dossiers (poor management of archives). In spite of these constraints, we feel that we have determined the epidemiological aspects of immediate postpartum hemorrhage at the University Hospital Centre (UHC). This hospital and mono-centric survey does not reflect the epidemiological reality at the level of the whole country. However, it is an advocacy tool to improve the filling out and maintenance of admission and follow-up records in the delivery room.

\section{Prevalence Of Ipph}

The prevalence of immediate postpartum hemorrhage was $1.6 \%$. While this prevalence varies from $0.86-$ $9.0 \%$ according to studies reported in some countries $(5,7,12,13,14,15,16,17,18)$. In population-based studies, the incidence of PPH is around $5 \%$ of deliveries when blood loss is not accurately measured, and around $10 \%$ when blood loss is accurately measured (19). The variation in prevalence for our case during these years could be explained by the fact that not all cases of hemorrhage were reported in the registries. This was due to some low-level hemorrhages that went unnoticed and the fact that this notion had not always been reported in the obstetrical records of the patients because of the burden of work. In addition, the census of maternal deaths at the hospital did not begin until 2014.

\section{Socio-demographic Characteristics}

The sociodemographic characteristics studied were age, occupation, marital status and educational level of women. 
Women between the ages of 20 and 39 were more represented with more than $80 \%$ of the workforce. However, there are variations in age frequency noted in Norway, Tunisia, France and Chad $(5,13,14,15$, 20). In a general review Deneux-Thenaux noted the same results (19). The high frequency of IPPH in this age group in our context could be explained by the fact that it corresponds to the period of increased female genital activity and fertility in the subregion. Any woman in the period of genital activity may be affected by immediate postpartum hemorrhage. Housewives and high school students were the most affected class with $45.0 \%$ and $84.5 \%$ respectively. This result could be explained by the fact that unemployment affects women almost twice as much as men in Gabon : 20 per cent compared to 11 per cent. The unemployment rate for young people under 30 years of age is $31 \%(21)$. IPPH seems to be more common among the disadvantaged strata, because of the inaccessibility of prenatal care and the management of the factors that contribute to it. And since the marital status of women aged 15-49 in Gabon is dominated by single and cohabiting couples (21), the study found that $92.7 \%$ of parturients were single.

\section{Women's Gynecological History}

The proportion of women with a history of cicatricial uterus was minimal, $1 \%$, in contrast to that reported by Chouaki in the Democratic Congo, 30.4\% (15). However, the proportion of women with a history of abortion was $45.6 \%$. It has been recognized that curettage and Caesarean section are causes of placenta previa and placental retention, which are risk factors for IPPH $(12,13)$. The absence of a history of IPPH or toxemia gravidarum in the records reviewed is to be deplored. In the partograms there is no entry mentioning these antecedents, which may be the reason for their absence. Nevertheless, Firmin et al. mentioned a significance between the history of IPPH and its occurrence (17). Partograms also do not show the estimated amount of blood loss. A new method for estimating blood loss should be adopted, as Andrikopoulou has pointed out (22). We noted a frequency of IPPH in pauciparum and primiparum with respectively $37.7 \%$ and $32.8 \%$ against $25.6 \%$ in multiparum. The same trend has been observed by some authors where IPPH was more frequent in paucipares $(13,18)$. Higher frequencies of IPPH in primiparous women have been observed in some studies while they have also been observed in multiparous women as shown in studies in Madagascar and Norway $(12,13)$. These results show that the frequency of IPPH is as high in pauci pares as in primipares. This could be explained by the overuse of uterotonics in these parturients in order to speed up labour ; the use of indigenous oxytocics at home, fetopelvic disproportions or prolonged labour in primiparous women are also incriminated.

\section{Characteristics Of Current Pregnancy And Childbirth}

There was no information on the modes and conditions of evacuation of these parturients, factors that may influence maternal and fetal management and prognosis. Pregnancies considered at term were the most observed and accounted for $53.1 \%$ and one third of deliveries were premature. In contrast to data from studies conducted in Madagascar and France, which found a higher frequency of full-term 
pregnancies than ours $(14,18)$. There is evidence that premature delivery can lead to placental retention complicated by delivery hemorrhage due to a cleavage defect between the placenta and the myometrium (23).

More than half of the parturients were not in labour when admitted. The other half had been in labour for an average of three hours and $5.2 \%$ of parturients had been in labour for at least 13 hours. In the dossiers explored, there was a lack of information concerning the profile of the staff who had taken immediate care of the parturients, as more than $3 / 4$ of women had gone directly to the hospital. Rakotozanany et al. showed that late referral and late management of parturients with IPPH are risk factors for maternal death (12). The majority of parturients had given birth by Caesarean section. In $2.2 \%$ of cases the extraction is done by forceps and an artificial delivery is done in $57.5 \%$ of cases. The frequency of these three procedures seems high since they are performed in the only reference hospital in the city that has an adequate technical platform.

\section{Etiologies And Risk Factors For Immediate Postpartum Hemorrhage}

Delivery haemorrhages accounted for $65.5 \%$ of IPPH, while genital traumas accounted for $59.9 \%$. These delivery haemorrhages are dominated by retroplacental haematoma, placenta previa and uterine atony. Some patients presented with one or two selected causes at the same time. These results are almost similar to the results obtained by some authors who have noted that uterine atony is the main cause of IPPH and that genital tract wounds are responsible for about 1 in 5 cases of IPPH (19). Thus, three of the three can be associated. They may be associated with: a pathology of delivery mainly represented by uterine inertia and placental retention; a uterine or vaginal genital lesion or a pathology of haemostasis $(24,25)$.

\section{The Hemorrhages Of Deliverance}

The main risk factors for IPPH in the most recent population-based studies vary from one author to another (19). In our study, primigravida and multi-gestations on the one side and primiparous and multiparous on the other appeared to have a lower risk of developing delivery hemorrhage. While women with preterm and postterm births, those with more than 12 hours of labor and those with a birth weight of less than 2500 grammes and more than 4000 grammes had a higher risk of developing IPPH. Multiparity, a factor contributing to uterine atony, has a non-negligible proportion in our study. Also, the use of oxytocics in our environment is very common, which could explain the frequency of uterine atony. In the occurrence of postpartum hemorrhages after vaginal delivery, the role of placenta previa is classic. The haemorrhage can be explained by the difficulties of uteroplacental cleavage and above all by the difficulties of spontaneous haemostasis. Also, the women's records did not allow us to note a history of $\mathrm{IPPH}$. 


\section{Trauma Of The Genital Tract}

In contrast to delivery bleeding, women aged 14-19 years are more likely to have genital tract trauma. These results are similar to those found in several studies (19). Indeed, this young age is exposed to lacerations of the cervix and perineum. We have also noted that women who have given birth at term, those who have children with a birth weight between 2500-4000 grammes and women who have given birth more than twice are more likely to have genital tract trauma. Still, in this study we have a proportion of $98.7 \%$ of women who underwent an artificial and assisted delivery; $51.6 \%$ of women had a caesarean section. These two factors are recognized as soft tissue tearing factors (26).

\section{Conclusions}

Immediate postpartum haemorrhage remains the most feared obstetric emergency in the delivery room, despite the existence of multiple management methods. The prevalence of immediate postpartum haemorrhage was $1.6 \%$. The parturients with the highest risk of IPPH were young women aged between 20 and 39 years, unmarried and from an unfavourable socioeconomic background as housewives or schoolchildren, with a secondary school education and having had at least one abortion and given birth at least once. The most common etiology was hemorrhage from the delivery due to a placental defect. Trauma to the genital tract was the second etiology. Multiparity remains the most common risk factor. IPPH is still the leading cause of maternal mortality in Gabon and the rest of the world. This is why it is important to improve management by better assessment of blood loss in the immediate postpartum period with the use of collection bags, saving time in diagnosis and management, close monitoring of the parturient and systematic delivery. The three aspects of treatment are inseparable, justifying adapted multidisciplinary care (obstetrician, anaesthetist, resuscitator, biologist): hence the interest in strengthening the capacities of health providers in terms of EmONC.

\section{Abbreviations}

\section{EmONC}

Emergency Obstetrical and Neonatal Care

IPPH

Immediate Postpartum haemorrhage

$\mathrm{PPH}$

PostPartum Heamorrhage

UHC

University Hospital Centre

WHO

World Health Organization

\section{Declarations}


Ethical approval : University of Health Sciences, Gabon approved this study

Consent for publication : Included in the submission system

\section{Availability of data and materials}

The datasets used and analysed during the current study available from the corresponding author on reasonable request. The datasets generated and/or analysed during the current study are not publicly available due to the promise made to health staff to keep the data confidential when they are questioned, but are available from the corresponding author on reasonable request.

Competing interests : The authors declare no conflict of interest

Fundings : None

\section{Authors' contributions :}

NAL and SHW designed the study, wrote the protocol and text and supervised the data analysis. LAOO, FEYM, VNST and EOA participated in the drafting of the protocol, data analysis and text writing. AJK participed in text writing and proofreading. All authors have read and approved the manuscript and contributed equally.

\section{Acknowledgements :}

The authors would like to thank the Ministry of Health of Gabon

\section{References}

1. Tunçalp O, Souza JP, Gülmezoglu M. New WHO recommendations on prevention and treatment of postpartum hemorrhage. Int J Gynaecol Obstet. 2013;123(3):254-6.

2. Subtil D, Somme A, Ardiet E, Depret-Mosser S. Post-partum haemorrhage: frequency, consequences in terms of health status, and risk factors before delivery. J Gynecol Obstet Biol Reprod 2004; 33(8) : 4S9-4S16.

3. Dolley P, Beucher G, Dreyfus M. Initial obstetrical management of port-partum haemorrhage following vaginal delivery. J Gynecol Obstet Biol Reprod. 2014;43(1):998-1008.

4. Khan KS, Wojdyla D, Say L, Gùlmezoglu AM, Van Look PF. WHO analysis of causes of maternel death: a systematic review. Lancet. 2006;367:1066-74.

5. Gabkika BM, Djongali S, Oumarou GS, Atade SR, Adoum T. Immediate postpartum haemorrhage:Epidemiological aspects and maternal prognosis at South N'Djamena District Hospital (Chad). South Sudan Medical Journal. 2015;8(2):28-32.

6. Say L, Chou D, Gemmill A, Tunçalp Ö, Moller AB, Daniels J, Gülmezoglu AM, Temmerman M, Alkema L. Global causes of maternal death: a WHO systematic analysis. Lancet Glob Health $2014 ; 2(6)$ : 
e323-33.

7. Waterstone M, Bewley S, Wolfe C. Incidence and predictors of severe obstetric morbidity: case-control study. BMJ. 2001;322(7294):1089-93.

8. Ministry of Health/ UNFPA. National report on maternal deaths in Gabon 2012-2015. [Cited on 24th March 2020]. Available on:

https://www.undp.org/content/dam/gabon/docs/Country\%20team/UNFPArapport\%20sur\%20les\%20d\%c3\%a9c\%c3\%a8s\%20maternels\%202012-2015.pdf.

9. King JC. Strategies to reduce maternal mortality in developed countries. Curr Opin Obstet Gynecol $2013 ; 25(2): 117-23$.

10. Abouchadi S, Alaoui AB, Meski FZ, Bezad R, De Brouwere V. Preventable maternal mortality in Morocco: the role of hospitals. Trop Med Int Health. 2013;18(4):444-50.

11. Lori JR, Starke AE. A critical analysis of maternal morbidity and mortality in Liberia, West Africa. Midwifery. 2012;28(1):67-72.

12. Deneux-Tharaux C, Bonnet MP, Tort J. Epidemiology of post-partum haemorrhage. J Gynecol Obstet Biol Reprod. 2014;43(10):936-50.

13. Ministry of Economy, Employment and Sustainable Development/ UNDP and ICF International. Gabon Demographic and Health Survey 2012: Synthesis Report. Maryland: Calverton; 2013. 503 p.

14. Rakotozanany B, Randriamahavonjy R, Rabearizaka L, Ratsiatosika T, Randriambelomanana JA. Maternal mortality related to postpartum heamorrhage: a case-control study at the Befelatanana maternity of Madagascar. Int J Reprod Contracept Obstet Gynecol. 2019;8(1):121-26.

15. Chaouki M, Marwen N, Amjed A, Haykel M, Maha J. Severe postpartum hemorrhage, epidemiology and management at university hospital of Nabeul. Ann Afr Med. 2013;6(4):1492-98.

16. Andrikopoulou M, D'Alton ME. Postpartum hemorrhage: early identification challenges. Semin Perinatol. 2019;43(1):11-7.

17. Karlsson H, Pérez Sanz C. Postpartum haemorrhage. An Sist Sanit Navar. 2009;32(1):159-67.

18. Oyelese Y, Ananth CV. Postpartum hemorrhage: epidemiology, risk factors, and causes. Clin Obstet Gynecol. 2010;53(1):147-56.

19. Vendittelli F, Barasinski C, Pereira B, Lémery D. Incidence of immediate postpartum hemorrhages in French maternity units: a prospective observational study (HERA study). BMC Pregnancy Childbirth. 2016;16:242.

20. Firmin M, Carles G, Mence B, Madhusudan N, Faurous E, Jolivet A. Postpartum hemorrhage: incidence, risk factors, and causes in Western French Guiana. J Gynecol Obstet Hum Reprod. 2019;48(1):55-60.

21. Ononge S, Mirembe F, Wandabwa J, Campbell OM. Incidence and risk factors for postpartum hemorrhage in Uganda. Reprod Health 2016; 13-18.

22. Dupont C, Rudigoz RC, Cortet M, Touzet S, Colin C, Rabilloud M, Lansac J, Harvey T, Tessier V, Chauleur C, Pennehouat G, Morin X, Bouvier-Colle MH, Deneux-Tharaux C. Frequency, causes and risk 
factors of postpartum haemorrhage: a population-based study in 106 French maternity units. $\mathrm{J}$ Gynecol Obstet Biol Reprod. 2014;43(3):244-53.

23. Nyfløt LT, Sandven I, Stray-Pedersen B, Pettersen S, Al-Zirgi I, Rosenberg M, Jacobsen AF, Vangen S. Risk factors for severe postpartum haemorrhage: a case-control study. BMC Pregnancy Chilbirth $2017 ; 17: 17$.

24. Ngbalé RN, Koirokpi A, Goddot NMJ, Gaunefet CE, Songo-KetteT, Heredeibona LS, et al. Les hémorragies du post - partum immédiat à l'Hôpital Régional Universitaire de Bossangoa, Centrafrique. Med Afr Noire. 2012;59(1):39-43.

25. Lacomme M. Pratique obstétrique, (Tome I) Masson; Paris 1960: 127-131.

26. Beucher G. Maternal morbidity after operative vaginal delivery. J Gynecol Obstet Biol Reprod. 2008;37(1):244-59.

\section{Supplementary Files}

This is a list of supplementary files associated with this preprint. Click to download.

- CONSENTFORM.pdf 